\title{
Being right or being happy: pilot study
}

\author{
@ $\mathbb{Q} \Theta$ OPEN ACCESS
}

\author{
Bruce Arroll professor, Felicity Goodyear-Smith professor, Simon Moyes statistician, Timothy Kenealy \\ associate professor
}

Department of General Practice and Primary Health Care, University of Auckland, Private Bag 92019, Auckland, New Zealand

\section{Introduction}

Three of the authors are general practitioners who see many patients and couples who lead unnecessarily stressful lives by wanting to be right rather than happy. Mathieu encourages her psychotherapy clients "to try to live in the gray. There are a million shades of gray" (although a recent erotic novel suggests there are only 50) "on the spectrum of white to black, and each provides a much richer telling of a story that is hardly ever as clear as this or that. So, when we looked a bit more closely, we saw that 'right versus happy' was not so much about getting crowned the winner or loser, a genius or fool; it was more about flawed thinking and a desire to want to feel being in control." This might be the first study to systematically assess whether it is better to be right than happy; a Medline search in May 2013 found no similar articles. Our null hypothesis was that it is better to be right than happy.

\section{Participants, setting, and design}

To be eligible participants had to be part of a couple and willing to take part in the study. We carried out a parallel trial with one man and one woman in their own home. It was decided without consultation that the female participant would prefer to be right and the male, being somewhat passive, would prefer to be happy.

The male was informed of the intervention while the female participant was not (this form of pre-randomisation is known as the Zelen method $^{2}$ ). The female participant was blind to the hypothesis being tested, other than being asked to record her quality of life.

\section{Intervention}

The intervention was for the male to agree with his wife's every opinion and request without complaint. Even if he believed the female participant was wrong, the male was to bow and scrape.

\section{Main outcome measure}

We measured quality of life with a Likert score of 1 to 10 (10 being the best possible quality of life). Although our tool was unvalidated, it was thought to have face validity. It was justified on the grounds that brevity was essential, given that the intervention was administered in a potentially complex domestic environment.

\section{Results}

Two participants were eligible and both (100\%) were randomised. All participants received the treatment and were analysed for the primary outcome with an intention to treat analysis. Several baseline characteristics differed between the subjects (see appendix).

The data safety monitoring committee stopped the study because of severe adverse outcomes after 12 days. By then the male participant found the female participant to be increasingly critical of everything he did. The situation had become intolerable by day 12 . He sat on the end of their bed, made her a cup of tea, and said as much; explained the trial and then contacted the Data Safety Monitoring committee who terminated the trial immediately.

There were three data points in the intervention group and two in the control group (the control participant had become hostile to recording her quality of life).

The man's quality of life score had fallen from 7 out of 10 at baseline to 3 at 12 days; the women's had increased slightly from 8 to 8.5 at six days (figure $\downarrow$ ). The difference between the two participants' QOL scores over time is significantly different $(\mathrm{P}=0.004$, calculated with a repeated measures generalised linear model). We should treat the results cautiously because we cannot discount causes other than treatment reducing the male participant's score. It seems that being right, however, is a cause 
of happiness, and agreeing with what one disagrees with is a cause of unhappiness. We cannot discount that the difference in results might be caused by differences between the two treatment groups, which unfortunately we were unable to match by possible confounders such as sex.

The harms were estimated as $100 \%$ as all participants who received the intervention reported a serious adverse event.

\section{Discussion}

The results of this trial show that the availability of unbridled power adversely affects the quality of life of those on the receiving end.

\section{Strengths and weaknesses}

The study has some limitations. There was no trial registration, no ethics committee approval, no informed consent, no proper randomisation, no validated test instrument, and questionable statistical assessment. We used the eyeball technique for single patient trials which, as Sackett says, "more closely matches the way we think as clinicians." ${ }^{3}$

\section{Generalisability}

Many people in the world live as couples, and we believe that it could be harmful for one partner to always have to agree with the other. However, more research is needed to see whether our results hold if it is the male who is always right.

Contributors: All authors read drafts of the document and the final version. FGS came up with the title and overall concept, SM did the statistical analysis, and BA saw the need for a clinical trial and conducted the trial, wrote the first draft and organised the team. TK was on the data safety monitoring committee.

Competing interest: None declared.

$1 \quad$ Mathieu I. Emotional sobriety. Psychology Today 2011.

2 Friedman ML, Fruberg CD, DeMets DL. Fundamentals of clinical trials. Springer-Science, 1998.

3 Sackett DL. Clinical trialist round 4. Why not do an N-of-1 RCT. Clin Trials 2011;8:350-2. Accepted: 27 November 2013

\section{Cite this as: BMJ 2013;347:f7398}

This is an Open Access article distributed in accordance with the Creative Commons Attribution Non Commercial (CC BY-NC 3.0) license, which permits others to distribute, remix, adapt, build upon this work non-commercially, and license their derivative works on different terms, provided the original work is properly cited and the use is non-commercial. See: http://creativecommons.org/licenses/by-nc/3.0/. 


\section{Figure}

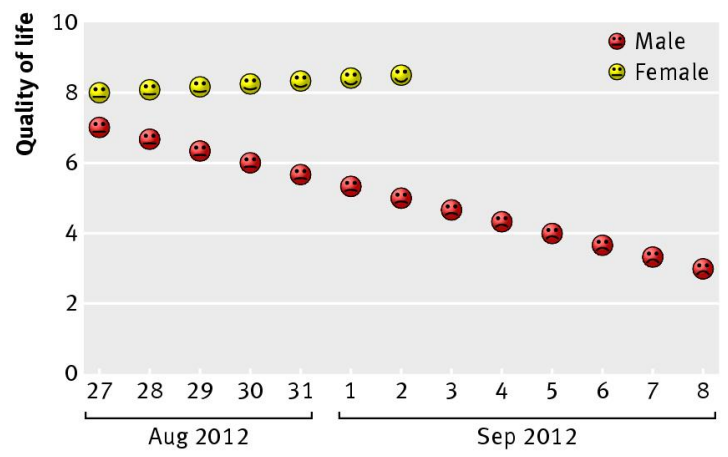

Quality of life by duration of intervention 